\title{
Editorial: Future Climate Scenarios: Regional Climate Modelling and Data Analysis
}

\author{
Xander Wang ${ }^{1,2 *}$, Yurui Fan ${ }^{3}$, Shan Zhao ${ }^{4}$, Yulie Xie ${ }^{5}$ and Hans Von Storch ${ }^{6}$ \\ ${ }^{1}$ Canadian Centre for Climate Change and Adaptation, University of Prince Edward Island, St. Peter's Bay, PE, Canada, \\ ${ }^{2}$ School of Climate Change and Adaptation, University of Prince Edward Island, Charlottetown, PE, Canada, ${ }^{3}$ College of \\ Engineering, Design and Physical Sciences, Brunel University London, Uxbridge, United Kingdom, ${ }^{4}$ School of \\ Environmental Science and Engineering, Shandong University, Qingdao, China, ${ }^{5}$ Institute of Environmental and Ecological \\ Engineering, Guangdong University of Technology, Guangzhou, China, ${ }^{6} \mathrm{Helmholtz}$ Centre for Materials and Coastal \\ Research (HZG), Geesthacht, Germany
}

Keywords: regional climate projections, climate change monitoring, hydrological modeling, climate change impacts and adaptation, climate modeling

\section{Editorial on the Research Topic}

\section{Future Climate Scenarios: Regional Climate Modelling and Data Analysis}

While climate change has become one of the most pressing issues around the world, adapting to it from a long-term perspective is extraordinarily challenging due to the significant spatial variations of climatic changes (e.g., different magnitudes of temperature increases from low- to high-latitude regions, precipitation increases in wet regions versus decreases in dry areas) as well as the wide variety of consequences caused by these changes (e.g., unexpected long-lasting droughts versus more frequent floods) (Giorgi, 2019; Wang et al., 2013). In order to support informed decision making and resilient engineering planning under future climate change, it is extremely important to develop reliable and high-resolution climate scenarios to facilitate the exploration of all possible changes to regional climatology and to quantify the potential climate risks to human society and natural systems (Wang et al., 2014; Wang et al., 2019).

Although global climate models (GCMs) have been widely used to develop future climate scenarios, their outputs are usually too coarse to be suitable for driving impact models which require finer-resolution projections at both spatial and temporal scales (Guo et al., 2018). Besides, there are a wide variety of uncertainties in future climate projections which are caused by different choices of greenhouse gas emissions scenarios, GCMs, physical parameterization schemes, etc. These challenges are among the most urgent issues to be addressed for climate change impact assessment and adaptation studies. High-resolution regional climate models, statistical downscaling, and advanced data analytical techniques are critically important to address these challenges, yet they are not well explored due to the research gaps among climate physicists, climate modellers, climate impacts modellers, and climate data users.

Therefore, this research topic aims to capture recent advances in regional climate modelling and data analysis in support of developing high-resolution climate scenarios and assessing regional climate change impacts. This editorial intends to provide a summary about all the papers collected in this research topic. In this research topic, we have published 22 original research articles authored by 109 researchers. The topics of these articles do span a variety of areas but can be generally grouped into four research areas: regional climate projections, climate change monitoring, hydrological modeling, and climate change impacts and adaptation. Here we endeavor to summarize the 22 published articles according to these four research areas. 


\section{REGIONAL CLIMATE PROJECTIONS}

Due to the significant spatial variations of climate change, developing high-resolution climate scenarios is the starting point for climate change impact assessment and adaptation at regional and local scales. This is because the decision makers and local stakeholders need to first understand what would be the expected climate before taking any mitigation and adaptation actions. In this research topic, we collected five research articles related to regional climate projections.

- The paper entitled "Ensemble Temperature and Precipitation Projection for Multi-Factorial Interactive Effects of GCMs and SSPs: Application to China" by Duan et al. evaluate the plausible changes in annual precipitation and mean temperature over China using five GCMs (i.e., CESM2, GFDL-ESM4, IPSL-CM6A-LR, MIROC6, and MRI-ESM2-0) under two Shared Socioeconomic Pathways (SSPs), including SSP2-4.5 and SSP5-8.5. A multi-level factorial analysis approach is then used to help explore and quantify the sources of uncertainty associated with the future climate projections for China.

- The paper entitled "Long-Term Maximum and Minimum Temperature Projections Over Metro Vancouver, Canada" by Tian et al. use a neural-network-based statistical downscaling model to help develop future temperature projections for Metro Vancouver, Canada. The model's performance is validated and demonstrated to be effective in simulating the regional temperature patterns of Metro Vancouver through comparisons between model simulations and observations.

- The paper entitled "Detection, Attribution, and Future Response of Global Soil Moisture in Summer" by Qiao et al. use the CMIP6 global climate scenarios and two global reanalysis datasets (i.e., ERA5 and GLDAS) to help detect, attribute, and project soil moisture variations at global scale. The result suggests that the anthropogenic forcings with consideration of greenhouse gases emissions, aerosols, and land cover and land use change have much large impacts on soil moisture variations than the nature forcing only.

- The paper entitled "Evaluation of the Ability of CMIP6 Global Climate Models to Simulate Precipitation in the Yellow River Basin, China" by Wang et al. apply the rank score method with consideration of eight performance indicators to evaluate the performance of the 19 selected GCMs from CMIP6 in simulating the regional climatology over the Yellow River Basin in China. The evaluation results can be used to help choose the appropriate GCMs for projecting high-resolution regional climate over the study area.

- The paper entitled "A Stepwise-Clustered Simulation Approach for Projecting Future Heat Wave Over Guangdong Province" by Ren et al. employ a stepwiseclustered simulation approach to perform climate downscaling to multiple global climate models under two representative concentration pathways (RCPs), with the purpose of projecting the future changes in heat waves for Guangdong Province, China. Four indicators have been used to evaluate the potential changes in heat waves, including intensity, total intensity, frequency, and the longest duration.

\section{CLIMATE CHANGE MONITORING}

Monitoring the long-term climate is fundamentally important for understanding what has occurred with our global and local climates. In addition, historical climate observations are widely used by climate scientists to improve our understanding of the physical and dynamical processes of the Earth's climate system and thus to develop better climate models through model validation and continuous performance improvement. In this research topic, we collected seven research articles related to climate change monitoring.

- The paper entitled "Lidar Observed Optical Properties of Tropical Cirrus Clouds Over Gadanki Region” by Kumar and Venkatramanan use the polarization-diversity groundbased Lidar measurements to help monitor and investigate the optical properties of high-altitude cirrus clouds. The authors demonstrate that the Lidar measurements can be used to study the cloud layer statistics (i.e., altitude variations of optical depth and depolarization ratio) and the seasonal variations in the optical properties of cirrus clouds.

- The paper entitled "Quantitative Estimation on Contribution of Climate Changes and Watershed Characteristic Changes to Decreasing Streamflow in a Typical Basin of Yellow River" by Lv et al. use the observational streamflow and meteorological datasets from 1958 to 2017 to quantify the relative contributions of climate change and the changes in watershed characteristics to streamflow change in the Huangshui River Basin of the Qinghai-Tibetan Plateau, China. The Budyko hypothesis test is used to perform the statistical analysis.

- The paper entitled "Long-Term Spatial and Temporal Variation of Near Surface Air Temperature in Southwest China During 1969-2018” by Zhou and Lu employ an improved ANUSPLIN model to analyze the trends, anomalies, change points, and variations of near surface air temperature for Southwest China. The observational data from 494 weather stations during the period of 1969-2018 are used to support the analysis.

- The paper entitled "Summertime Moisture Sources and Transportation Pathways for China and Associated Atmospheric Circulation Patterns" by Zhang et al. use the Lagrangian particle dispersion model (HYSPLIT) to quantitatively analyze the impacts of major atmospheric moisture sources from Midlatitude Westerly, SiberianArctic regions, Okhotsk Sea, Indian Ocean, South China Sea, Pacific Ocean, and China Mainland on the summertime precipitation patterns in China. The ERA-Interim reanalysis 
dataset is used to derive the input data needed for the HYSPLIT model, including 6-hourly and monthly geopotential height, horizontal and vertical wind, 2-m temperature, sea surface temperature, evaporation, precipitable water, and precipitation during the period of 1979-2017.

- The paper entitled "Interdecadal Linkage Between the Winter Northern Hemisphere Climate and Arctic Sea Ice of Diverse Location and Seasonality" by $\mathrm{He}$ et al. investigate the possible linkage between the mid-high-latitude atmospheric circulation and Arctic sea-ice loss on interdecadal timescales for the period of 1959-2020. The datasets used in this study include the National Centers for Environmental Prediction atmospheric reanalysis data, the monthly sea-ice concentration (SIC) from the Met Office Hadley Center, and the enhanced monthly mean precipitation from the Climate Prediction Center Merged Analysis of Precipitation.

- The paper entitled "Characteristics of Precipitation During Meiyu and Huang-Huai Rainy Seasons in Anhui Province of China" by Zhou et al. use the China's Meiyu monitoring indices to explore the precipitation characteristics of the Anhui Province, China during the Meiyu and Huang-Huai Rainy seasons. The observational climate data from 15 weather stations in the Anhui Province during the period of 1975-2020 were used to conduct the analysis.

- The paper entitled "Change in Extreme Precipitation Over Indochina Under Climate Change From a Lagrangian Perspective of Water Vapor" by Cheng et al. explores how global warming has humidified the atmosphere and increased the occurrence of extreme precipitation events over the Indochina Peninsula during the period of 1951-2015. A variety of climate observational and reanalysis datasets (e.g., the APHRODITE data, the ERA5 global reanalysis, and the NOAA ERSST.v5) are used here to support the analysis.

\section{HYDROLOGICAL MODELING}

As the hydrological cycle has been intensified by global warming, the conventional stationary assumption in many existing hydrological and hydraulic projects has been demonstrated to be inappropriate. Therefore, how to develop robust hydrological models to simulate the changing precipitation-streamflow or rainfall-runoff relationships under non-stationarity has become one of the top research priorities towards climate change. In this research topic, we collected five research articles related to hydrological modeling under climate change.

- The paper entitled "A Statistical Hydrological Model for Yangtze River Watershed Based on Stepwise Cluster Analysis" by Wang et al. propose a stepwise cluster analysis hydrological model to simulate the nonlinear and dynamic rainfall-runoff relationship. The developed model has been applied to the Yangtze River Watershed to predict the runoff responses to regional climatic conditions.

- The paper titled "Risk Assessment of Dam-Breach Flood Under Extreme Storm Events" by Lin et al. propose a hydrodynamic modelling approach to perform flood inundation simulations under various dam-breach scenarios caused by extreme rainfall events. A comprehensive case study for the Mountain Island Dam within the Catawba River Watershed of North Carolina, United States has been presented to demonstrate the effectiveness of the proposed approach in assessing the dam-breach flooding risks under extreme storm events.

- The paper entitled "A Bayesian-Model-Averaging Copula Method for Bivariate Hydrologic Correlation Analysis" by Wen et al. incorporate the Bayesian model averaging method and Archimedean Copula techniques into a general modeling framework to help analyze and quantify the correlations between rainfall and runoff. A case study for the Xiangxi River Watershed in China has been introduced to demonstrate the effectiveness of the proposed methodology.

- The paper entitled "Changes in and Modelling of Hydrological Process for a Semi-Arid Catchment in the Context of Human Disturbance" by Liu et al. investigate the applicability of a flood forecasting model (i.e., GR4J) for a semi-arid region under a changing environment. The Zhulong River Catchment in North China is used as a case study to evaluate the performance of GR4J model in simulating the hydrological processes from 1967 to 2015.

- The paper entitled "Water Resources Availability Assessment Through Hydrological Simulation Under Climate Change in Huangshui Watershed of QinghaiTibet Plateau" by $\mathrm{Fu}$ et al. propose a hydroclimate modeling framework through the integration of the Statistical Downscaling method (SDSM), Generalized Regression Neural Network (GRNN) model, Soil and Water Assessment Tool (SWAT) model, and the improved Tennant method. Through its application for the Huangshui Watershed of the Qinghai-Tibet Plateau in China, the proposed modeling framework is demonstrated to be effective in enhancing the spatial resolution of the predicted meteorological and hydrological parameters under climate change.

\section{CLIMATE CHANGE IMPACTS AND ADAPTATION}

Developing sustainable and climate-resilient communities requires a comprehensive understanding of the potential impacts of climate change on various sectors (e.g., agriculture, fisheries, tourism, transportation, energy systems, urban infrastructure, human and animal health, and so on) and a feasibility evaluation for all potential climate adaptation measures. Since climate change is essentially affecting all aspects of our daily life, the research for climate change impacts and adaptation can span many disciplines by nature. 
In this research topic, we collected five research articles related to climate change impacts and adaptation.

- The paper entitled "The Effect of Precipitation on Hydropower Generation Capacity: A Perspective of Climate Change" by Wei et al. use the high-resolution precipitation data obtained from statistical climate downscaling to assess the potential changes to the hydropower potential in the Dadu River Basin in China. The results can provide a scientific basis for future water sources management, especially for the planning and operation of the hydropower station in the study area.

- The paper entitled "Facing Water Stress in a Changing Climate: A Case Study of Drought Risk Analysis Under Future Climate Projections in the Xi River Basin, China" by Wang et al. present a case study about drought risk analysis in the Xi River Basin, China under future climate change scenarios. The CMIP5 climate data and the VIC model are used to generate precipitation and runoff data for the drought risk assessment.

- The paper entitled "A Low-Impact Development-Based Multi-Objective Optimization Model for Regional Water Resource Management under Impacts of Climate Change" by Bao et al. propose a mathematical optimization model to help incorporate multiple uncertainties and climate change into a multi-objective decision making framework to support regional water resources management. The model considers a variety of adaptive water allocation alternatives and construction schemes associated with low-impact development to support climate change adaptation in an urban environment.

- The paper entitled "Impact of Climate Change on Water Availability in Water Source Areas of the South-to-North Water Diversion Project in China" by Qiao et al. evaluate

\section{REFERENCES}

Giorgi, F. (2019). Thirty Years of Regional Climate Modeling: where Are We and where Are We Going Next? J. Geophys. Res. Atmospheres 124 (11), 5696-5723.

Guo, J., Huang, G., Wang, X., Li, Y., and Lin, Q. (2018). Dynamically-downscaled Projections of Changes in Temperature Extremes over China. Clim. Dyn. 50 (3), 1045-1066. doi:10.1007/s00382-017-3660-7

Wang, X., Huang, G., Lin, Q., Nie, X., Cheng, G., Fan, Y., et al. (2013). A Stepwise Cluster Analysis Approach for Downscaled Climate Projection - A Canadian Case Study. Environ. Model. Softw. 49, 141-151. doi:10.1016/j.envsoft.2013.08.006

Wang, X., Huang, G., and Liu, J. (2014). Projected Increases in Intensity and Frequency of Rainfall Extremes through a Regional Climate Modeling Approach. J. Geophys. Res. Atmospheres 119 (23), 13-271. doi:10.1002/2014jd022564

Wang, X., Kinsland, G., Poudel, D., and Fenech, A. (2019). Urban Flood Prediction under Heavy Precipitation. J. Hydrol. 577, 123984. doi:10.1016/j.jhydrol.2019. 123984 the water availability challenges for the mega water project in China-the South-to-North Water Diversion project, in the context of climate change. A grid-based RCCC-WBM model is used here to develop runoff scenarios driven by GCMs, in order to assess the water supply risks under a changing climate.

- The paper entitled "Projecting Hydrological Responses to Climate Change Using CMIP6 Climate Scenarios for the Upper Huai River Basin, China" by Bian et al. investigate how global warming would affect the regional hydrological characteristics of the Upper Huai River Basin, China by using the CMIP6 climate scenarios and the Xinanjiang hydrological model. The results can provide a scientific basis for the local stakeholders and decision makers to develop appropriate flood mitigation and water utilization strategies in the context of climate change.

We hope that the readers will find this research topic interesting and the published papers will stimulate further research advancement towards climate change monitoring, modeling, impact assessment, and adaptation at regional and local scales.

\section{AUTHOR CONTRIBUTIONS}

XW wrote the first draft of this editorial. All authors contributed to manuscript revision, read, and approved the submitted version.

\section{ACKNOWLEDGMENTS}

We would like to thank all the authors for their contributions and all the reviewers for their valuable comments and feedback.

Conflict of Interest: The authors declare that the research was conducted in the absence of any commercial or financial relationships that could be construed as a potential conflict of interest.

Publisher's Note: All claims expressed in this article are solely those of the authors and do not necessarily represent those of their affiliated organizations, or those of the publisher, the editors and the reviewers. Any product that may be evaluated in this article, or claim that may be made by its manufacturer, is not guaranteed or endorsed by the publisher.

Copyright (c) 2022 Wang, Fan, Zhao, Xie and Von Storch. This is an open-access article distributed under the terms of the Creative Commons Attribution License (CC $B Y$ ). The use, distribution or reproduction in other forums is permitted, provided the original author(s) and the copyright owner(s) are credited and that the original publication in this journal is cited, in accordance with accepted academic practice. No use, distribution or reproduction is permitted which does not comply with these terms. 